\title{
Nitrogen Comes Down to Earth: Report from the 5th European Nitrogen Fixation Conference
}

\author{
Peter De Hoff ${ }^{1}$ and Ann M. Hirsch ${ }^{1,2}$ \\ ${ }^{1}$ Molecular Biology Institute and ${ }^{2}$ Department of Molecular, Cell and Developmental Biology, University of California, \\ Los Angeles, CA 90095-1606 U.S.A.
}

Submitted 6 January 2003. Accepted 21 January 2003.

For four days and four nights, with almost 50 presentations and more than 175 posters, the 5th European Nitrogen Fixation Conference continued a tradition of excellence, bringing scientists from diverse fields such as microbiology, biochemistry, computational genomics, and plant physiology together to address the complex problems associated with biological nitrogen fixation (BNF). The conference was hosted by the John Innes Center and the University of East Anglia in Norwich, England and took place from September 6 through 10, 2002. A diverse range of topics was presented, from the evolution of rhizobial genomes to the plant genes involved in bacterial and fungal symbiosis, to the structure of nitrogenase, and to the means by which nitrogen is shuttled between the symbiotic bacteria and the plant. Additionally, sessions involving broader issues, such as nitrogen fertilizer use and work being done in developing countries, brought home the importance of the research being carried out in BNF around the world.

When spending long hours in the lab doing "bench science," the practical consequences of biological nitrogen fixation (BNF) research seem remote. The first three speakers, who were introduced by Sir John Beringer (Bristol, U.K.), set the tone for the conference, bringing the audience's attention to the real world benefits of BNF research. For example, the use of nitrogen fertilizers is on the rise globally, while developing countries struggle not only with higher costs for these fertilizers but also with dwindling land and water resources to surmount the burden of feeding their ever-increasing populations. These points were illustrated in a talk by Jules Pretty (Essex, U.K.), who reminded everyone that food security, still an unmet need throughout most of the world, will require more than just growing food for more people on less land. If there is not enough emphasis placed on managing the reduced land available for agriculture or fertilizer to restore nutrient-depleted soils brought about by existing agricultural practices, there will be insufficient food and, with it, the potential for social and political unrest. Peter Goddard (Porsgrunn, Norway) described the different types of nitrogen fertilizers that are available to farmers, mentioning that, although nitrogen is the current limiting factor for plant growth, it is not the only one, with 13 essential minerals supplied from the soil, particularly phosphorous, representing potential bottlenecks in the future. Peter

Corresponding author: A.M. Hirsch; Telephone: 1-310-206-8673; Fax: 1310-206-5413; E-mail: ahirsch@ucla.edu
Gresshoff (Brisbane, Australia) gave a brief history of the last 20 years of symbiosis research from both the bacterial and the plant sides of the equation. He introduced a theme that would be reiterated throughout the molecular course of the conference, the importance of synteny of genetic sequences across species as a tool to identify significant genes.

Receptor kinases rule the day.

Description of the genes involved in the plant recognition of symbiont-produced signals was a major emphasis in several talks. Gyorgy Kiss (Szeged, Hungary) described his results and those from his group based on the tireless years of map-based cloning of the mutated gene responsible for the $\mathrm{Nod}^{-}$phenotype of the alfalfa genotype known as MN1008. The MN1008 allele is mutated in the kinase domain of a nodule receptor kinase (NORK) signaling protein. The orthologs in other legumes include SYM19 in Pisum sativum and DMI2 in Medicago truncatula. Martin Parniske (Norwich, U.K.) also described a NORK ortholog, designated SymRK, for Lotus japonicus. The cloning and identification of genes encoding NORK and SymRK were recently published (Endre et al. 2002; Stracke et al. 2002).

As the developmental pathways between nodulation and mycorrhizae formation partially overlap, some hypothesize that the NORK/SymRK protein is a receptor for a microbial-derived signal in both the nodulation and mycorrhizal pathways, because gene knockouts eliminate symbiotic responses to both rhizobia and the fungus. There are also proteins that appear to act upstream of NORK/SymRK, based on the $\mathrm{Nod}^{-} \mathrm{Myc}^{+}$ phenotypes of certain legumes. Clare Gough (Toulouse, France) and Simona Radutoiu (Aarhus, Denmark) described mutants of M. truncatula (Mtnfp) and L. japonicus (Ljsym1), respectively, that are phenotypically identical to the Pisum sativum sym 10 and $L$. japonicus sym 5 mutants. Genes specific to bacterial symbiosis would thus include the MtNFP or LjSYM1 genes, as well as PSSYM10 and LjSYM5, because plants with mutations in these genes do not perceive the presence of rhizobia yet form arbuscular-mycorrhizal (AM) associations. Progress in the mapping and positional cloning of these upstream effectors was described here as well as in a poster presented by Esben B. Madsen of the Stougaard group (Aarhus, Denmark). Whether or not these genes also encode receptor kinases awaits further investigation.

Another receptor kinase was described by Lene Krussell (Aarhus, Denmark). This receptor kinase is not involved in early signaling events but rather in the regulation of root and nodule development, particularly a breakdown in autoregulation, i.e. when too many nodules form on a root. A number of 
years ago, Peter Gresshoff (Carroll et al. 1985) described the $n t s$ mutant of soybean, which overproduces nodules even in the presence of a high concentration of nitrate. The harl mutant of L. japonicus has a similar phenotype. By a map-based cloning approach, the harl mutation was localized to the lower arm of linkage group 3, and comparison of this region with a syntenous region in Arabidopsis suggested a candidate gene, namely CLAVATA1, a serine-threonine kinase that is important for restricting the floral meristem in Arabidopsis. Gresshoff's group has found a similar gene accounting for the supernodulation phenotype in soybean. The identity of the protein or ligand with which HARl is interacting is unknown, but as for CLAVATA1 in Arabidopsis, there may be a legume homolog of CLAVATA3. These results have been recently published (Krussell et al. 2002; Nishimura et al. 2002; Searle et al. 2002).

\section{Microbial communication.}

The research on mutants that are $\mathrm{Nod}^{-}$and $\mathrm{Myc}^{+}$suggests the possibility of a separate signal being produced by the mycorrhizal fungus. It is well known that a signal promoting hyphal branching is secreted by the plant and is perceived by the fungus, even if the two partners are separated from each other by a membrane (Buée et al. 2000). Because of the similarity of downstream responses in the nodulation and mycorrhizal developmental pathways, there has been speculation that the fungal signal molecule resembles Nod factor, if not in structure, then perhaps in function. Although van Rhijn and associates (1997) were unable to find a nodC homolog in Glomus intraradices by polymerase chain reaction or genomic Southern analysis, absence of evidence is not necessarily evidence of absence of a Nod factor-like molecule in AM fungi. David Barker (Toulouse, France) reported on a putative secreted fungus factor with functional similarity to rhizobial Nod factor. This factor was detected by the use of ENOD11/12 promoterGUS fusions to show that the plant can respond to the presence of the mycorrhizal fungus, even if it is physically separated from the plant root by a permeable barrier. The fact that there are cis elements in the promoters of the marker genes that are Nod factor-responsive would suggest that if the separated fungus induced the ENOD11/12 promoter GUS fusions, a signal with similarity to Nod factor should exist. Indeed, blue color indicative of GUS activity was observed in the root hairs of Agrobacterium rhizogenes-transformed M. truncatula 72 hours postinoculation. Although this work did not take into account the plant's response to fungally produced cytokinin, a hormone that has been shown to induce the expression of at least two ENOD genes (Bauer et al. 1996; Fang and Hirsch 1998), it does illustrate an interesting method to determine the existence of a putative secreted Myc factor.

In many associations between bacteria and their hosts, quorum sensing (QS) is important for colonization and infection of the host. QS is not only involved in plasmid transfer, unique phenotypes such as luciferase production in Vibrio fischeri, and adaptation to stress, but it is also important for biofilm formation. Like many bacteria, Rhizobium leguminosarum bv. viciae shows QS and also synthesizes more than one QS signal. Allan Downie (Norwich, U.K.) described the complex network of regulons that are important for $\mathrm{N}$-acyl-homoserine lactone (AHL) production and perception. One of these involves expR, which when mutated, results in decreased biofilm production by the mutant compared to wild-type $R$. leguminosarum bv. viciae. This behavior is explained by the fact that bacteria are not only recruited into biofilms but they also leave them. ExpR regulates a number of downstream genes, some of which encode glycanases that cleave exopolysaccharide. This reaction could promote release from the biofilm and reestablishment of the planktonic state.
Nodule development and invasion of the "-omes."

Moving beyond the genes involved in plant-microbe recognition, the mechanisms by which nodules are formed were discussed. These talks brought attention to localized plant oxidative burst responses to shape the nodules and the infection zone. Marcelle Holsters (Ghent, Belgium) reviewed her work on Azorhizobium caulinodans/Sesbania rostrata nodulation. The semiaquatic Sesbania rostrata plant forms both subterranean and aerial nodules. The crack entry mode of aerial nodule development is characterized by an ethylene-induced oxidative burst response that causes local cell death and opens up a pocket within which the symbiotic bacteria can live. Expanding on this idea was Karsten Niehaus (Bielefeld, Germany), who spoke on the modulation of the oxidative burst and the production of reactive oxygen species (ROS) in response to lipopolysaccharide molecules specific to Sinorhizobium meliloti. ROS may promote infection in that it results in the cross-linking of cell wall components in infection threads, making them resistant to hydrolytic enzymes. Alain Puppo (Nice, France) also presented data about ROS and its production early in the symbiotic interaction, as well as the involvement of nitric oxide (NO) in later nodule development. Specifically, the different expression patterns of the genes for catalase production (katA, B, and $C$ ) in different zones of the nodule suggest potential functions for each of the catalase enzymes.

Adam Kondorosi (Gif-sur-Yvette, France) described cell cycle control in the development of indeterminate nodules, particularly the phenomenon of endoreduplication (up to 64C) in zone II of the nodule. Based on studies of transgenic plants with overexpressed and antisensed constructs carrying $\operatorname{ccs} 52$, a cell cycle switch gene, he concluded that endoreduplication appears to be required for nodule development. Other genes important for nodule development were also described, including a nodule-specific gene family encoding glycine-rich proteins, some of which may be involved in signaling. Nodule-specific cysteine-rich proteins, which may also have defined roles in nodule development, were also described.

Katharina Pawlowski (Göttingen, Germany) detailed evidence obtained from using chimeric gene fusions of legume and actinorhizal ENOD40 promoters fused to GUS that pointed toward the role of ENOD40 in symplastic unloading of sugars in symbiotic tissues. She also showed that seeds from Arabidopsis thaliana plants containing a $35 \mathrm{~S}$ construct with the $\mathrm{Al}$ nus glutinosa ENOD40 did not germinate on a medium containing $6 \%$ sucrose. One possible explanation for this result is that the ectopic expression of ENOD40 affects symplastic transport. A poster from Martin Crespi's group (Gif-sur-Yvette, France) also illustrated a study of the role of ENOD40 in symplastic transport, using plasmodesmata-localized viral proteins fused to GFP to follow symplastic flow. The viral construct traveled via the phloem, its position marked by GFP, and clearly illustrated movement of GFP into the nodule via plasmodesmata. Also on the ENOD40 front, Pawlowski described her work on ENOD40 genes from the actinorhizal plant Alnus glutinosa. There is only one copy of ENOD40 in this genome, and although it has several open reading frames in the mRNA transcript, it lacks the typical conserved open reading frames found in other ENOD40 genes.

Alexey Borisov (St. Petersburg, Russia) described a hierarchy of nodule development based on the numerous mutants isolated for the well-studied and edible model legume, Pisum sativum. The display of 40 mutants at different steps of the establishment and maintenance of the nodule was a gentle reminder of the complex pathways of genes necessary for this symbiotic interaction. These mutants were physiologically characterized by their specific nodulation arrest points and grouped together. Additionally, he presented work regarding 
the transformation of the Rhizobium from the free-living bacteria state to the terminally differentiated bacteroid and how bacterial genes not involved in fixing nitrogen are essentially turned off as the bacteroid develops, changing what was once a free-living microorganism into little more than a nitrogen-fixing factory for the plant.

Efforts to identify global gene expression patterns in nodule transport, metabolism, and maintenance were addressed via micro- and macro-cDNA array technologies by Michael Udvardi (Golm, Germany) and Helge Küster (Bielefeld, Germany). Udvardi described his work deciphering some of the expression patterns of $L$. japonicus nodules via cDNA microarrays and metabolome and proteome gas chromatography/mass spectroscopy analysis. Using these techniques, a number of differentially expressed molecules, which are present in higher quantities in the nodule than in other parts of the plant, were isolated. Peptide transporter molecules were found to be present in larger quantities in the nodules, a finding that fits well with the work of Philip Poole on nitrogen transport from the rhizobia to the plant, described at this conference. Furthermore, Udvardi's work with the nodule expressed sequence tag (EST) project and cDNA microarrays pulled out over 800 genes that are more than twofold induced in the nodule and 600 additional genes that are just twofold induced. This EST work was complemented and extended by Küster's work with M. truncatula, which examined not only rhizobial-plant interactions but also AM symbioses. Over half of the top 23 genes induced by AM symbioses that were identified by Küster and colleagues were found to be of unknown function.

Moving into transcriptome analysis from the bacterial side, Jacques Batut (Toulouse, France) described his work with nylon membrane cDNA macroarrays of Sinorhizobium meliloti grown under various environmental conditions and continued with an examination of the expression patterns of rhizobia in mature (18 days postinoculation [dpi]) and young ( $8 \mathrm{dpi})$ nodules of $M$. truncatula. When in the nodule, a number of rhizobial genes showed increased expression levels, notably katA (but not $k a t C$ ), genes involved in iron metabolism, virulence-like genes, and some genes related to oxygen stress. These results were mostly complementary to some of the other work presented at this conference. Future studies should reveal more.

\section{Amino acid shuttles, nitrogenase, and regulation.}

Philip Poole (Reading, U.K.) talked about the elucidation of an amino acid shuttle between rhizobia and their host plant, which is required for the correct assimilation of fixed nitrogen by the plant. Previous theories about how nitrogen is assimilated by the plant involved the transport of ammonium and alanine directly to the plant tissue from the bacteroid. Glutamate is also postulated to be involved in this process, and the Poole group set out to test this hypothesis. Studying R. leguminosarum bv. viciae, Poole and colleagues identified a broad specificity amino acid ABC transporter molecule named Aap. When the gene encoding Aap was mutated, there was reduced glutamate transport yet no significant effect on the plant's ability to absorb nitrogen from the bacteroid. The group then went back to the bacteria and isolated another $\mathrm{ABC}$ transporter with extremely broad specificity, named Bra. When an aap-bra double mutant was generated, the host plants still formed nodules. However, the plants were now unable to absorb ammonium correctly and became chlorotic, in spite of the fact that the bacteroids were producing nitrogenase, fixing nitrogen, and transporting the ammonia to the plant. Although the work complementing the mutant bacteria with specific $E$. coli glutamate transporters has yet to be done, the body of evidence presented strongly suggests that the current model of nitrogen assimilation of the plant from the bacteroid needs to be revised.
Dennis Dean (Blacksburg, VA, U.S.A.) described his work regarding the determination of the region of the FeMo nitrogenase cofactor (FeMoco) that is most likely responsible for binding dinitrogen (Christiansen et al. 2000). This was accomplished through a series of elegant mutational studies in which strains of Azotobacter vinelandii were selected by their ability to grow in nitrogen-deficient medium in the presence of acetylene and nitrogen in the atmosphere. Dean proposed that acetylene and dinitrogen use the same site on the nitrogenase for reduction; however, acetylene is a much larger molecule than dinitrogen. Hence, alterations in the protein that sterically hinder the access of acetylene to FeMoco should still permit dinitrogen to enter the binding site. This turns out to be the case in that bacteria with an amino acid change of Gly69 to Ser69 survive in the acetylene-containing atmosphere. This amino acid substitution generates a conformational change in the binding pocket for acetylene that blocks its entry. However, the smaller dinitrogen molecule can access the site and get reduced, in this way permitting bacteria survival.

Several talks were given about the details of the inhibition and regulation of nitrogen fixation, either in free-living bacteria or in the nodule. Christopher Pickett (Norwich, U.K.) presented data on a synergism of $\mathrm{CO}$ and $\mathrm{CN}$ binding at the iron core of isolated FeMoco, whereas Daniel Kahn (Toulouse, France) described the conformational changes, deduced by crystallographic analysis, of FixJ in its native and phosphorylated states. He also presented results obtained by alanine scanning mutation analysis demonstrating that Phe101 in FixJ may be the critical amino acid for two-component signal transduction. Bernd Masepohl (Bochum, Germany) and Ruth Schmitz (Göttingen, Germany) described the complex regulatory networks in Rhodobacter capsulatus and Klebsiella pneumoniae, respectively. $R$. capsulatus is unusual in that it has two copies of nifA and has other gene duplications as well. It also is photosynthetic, so the regulatory link between photosynthesis and nitrogen fixation makes for a complex scheme. In K. pneumoniae, NifL lacks iron, but this element is required to relieve NifA inhibition under de-repressing conditions. Schmitz described her work on the global transcriptional regulator Fnr, which does contain iron and appears to regulate transcription of an electron donor required for the reduction of NifL. On the symbiotic side, Hans-Martin Fischer (Zürich, Switzerland) described a redox-regulatory network that controls symbiotic nitrogen fixation in Bradyrhizobium japonicum. Not only is a FixLJ two-component system under redox control in soybean nodules, but $B$. japonicum also has a RegSR-NifA cascade that is important for both nitrogen fixation and the expression of a large number of nonnitrogen fixation-related target genes.

\section{On an evolutionary note.}

Peter Young (York, U.K.) presented some of his work on the possible origin of bacterial genes. By comparing the frequencies of a $\mathrm{G}$ or $\mathrm{C}$ in the third base of a codon, where a change would be silent, he was able to determine whether a gene was chromosomal or plasmid-based. The idea being that if there is a change in this third base then, with the exception of codon bias, there is very little selection pressure on it, and hence, an estimate of mutation rate free of environmental pressures can be made. Using these criteria, chromosomal DNA has a higher $\%$ GC than plasmid DNA, thus permitting the identification of potential plasmid islands on some chromosomes as well as chromosomal islands on some plasmids. For example, in Mesorhizobium loti, the chromosomal DNA has a high GC content with the exception of a few "symbiotic islands," whereas the plasmids all have low GC content. On the other hand, Sinorhizobium meliloti plasmids are split, with pSymA having low GC and pSymB on the higher side with a few areas 
of low GC. This suggests that pSymB in S. meliloti may have had a complex history of rearrangement. This \%GC technique can also be applied to specific genes, lending support in arguments concerning whether they are of plasmid or chromosomal origin. For example, all of the nod genes in rhizobia have a low GC content, whereas $r e c A, a t p D, g \ln I I$, and $g \ln A$ all have high GC content.

John Sullivan (Dunedin, New Zealand) described the 502-kb symbiosis island of Mesorhizobium loti and examined whether or not other regions of DNA, or "fitness islands," have been integrated into the phe-tRNA locus. There was quite a bit of evidence for the existence of these conjugative self-transmissible site-specific integrating elements, or "constins." Several genes important for bacterial attachment, namely one coding an adhesin with a similarity to the outer membrane adhesins from Brucella, Yersinia, and Salmonella spp. were found. The significance of the presence of adhesin genes in at least three constins is not known.

Xavier Perret (Geneva, Switzerland) took a look at the "Universal Symbiont," NGR234, which nodulates more than 112 plant genera and reviewed flavonoid activation, the nod boxes-49-bp consensus sequences found upstream of nod gene operons-QS, and nif gene regulation for this Rhizobium strain. He also described a gene for a LuxR homolog $(\mathrm{q} 4 \mathrm{aH})$ that is highly expressed in nodules, suggesting that QS may be important for regulating gene expression in bacteroids. Other genes, designated $\mathrm{q} 4 \mathrm{aF}$ and $\mathrm{q} 4 \mathrm{aG}$, are also highly expressed in nodules. Although their function is unknown, they have homologs in other bacteria. From mutagenesis studies, it appears that some of these unknown genes may be important for optimizing symbiotic nitrogen fixation.

\section{Alternative strategies.}

With all of the talk about the internalized nitrogen-fixing symbiosis between rhizobia and the plant, it is important not to forget that there are other forms of BNF symbioses established that do not require a nodule. For example, Barbara ReinholdHurek (Bremen, Germany) talked about kallar grass and its ability to associate with Azoarcus sp. strain $\mathrm{BH} 72$ and to gain higher biomass under nitrogen-limiting conditions. Microarray analysis of soil RNA indicated that nitrogenase genes were upregulated, but it was not clear for which particular species. Furthermore, once inside the plant and fixing nitrogen, the bacteria lose their ability to be cultured, indicating dependence on the plant for that part of the life cycle. On the other hand, the work of Euan James (Dundee, U.K.) indicated that there were no bacteria that were responsible for nitrogen fixation on the inside of wetland rice roots. He based this conclusion on the fact that when roots are surface-sterilized, nitrogen fixation disappears. He hypothesized that most of the growth increase seen in endophyte-associated plants is due to bacterial hormone production and not to BNF. However, he left open the possibility that there were indeed unknown nitrogen-fixing endophytes that have yet to be isolated and also that epiphytic bacteria contribute fixed N. Needless to say, additional research is needed to resolve these exciting questions.

Cyanobacteria sometimes associate with plants and sometimes grow independently. To ensure nitrogen fixation in an oxygen-containing atmosphere, these microorganisms form specialized cells known as heterocysts. Antonia Herrero (Sevilla, Spain) described the regulatory network for heterocyst differentiation. The transcriptional regulator NtcA, which is important for global nitrogen control, is also required for heterocyst differentiation, but it first must activate the hetR and het $C$ genes. This is followed by HetR activating $n t c A$, and this increase in NtcA levels activates the expression of genes important for heterocyst differentiation and subsequent nitrogen fixation. Another talk on cyanobacteria, this one by F. J. Florencio (Sevilla, Spain) described the role of 2-oxoglutarate in signaling nitrogen status in Synechocystis sp. NtcA, the protein important for heterocyst differentiation, is also involved in the regulation of nitrogen assimilation.

\section{Real-life BNF.}

Several talks were presented about BNF for sustainable and low-input agriculture. This area of study also had the largest number of posters (35), describing topics as varied as the effects of stress on BNF, the identification of new strains, methods for inoculation, the performance of certain plant genotypes, novel associations between diazotrophs and plants, biofertilization, rhizobial diversity, and alternative cropping systems.

Bob Boddey (Seropédica, Brazil) noted that since the adoption of zero-tillage agriculture in Brazil, fuel and labor costs have decreased dramatically. Also, soil erosion has been significantly reduced, as has loss of mineral nitrogen. However, carbon accumulation in the soil was not improved until a nitrogen-fixing crop was included in the rotation cycle. N. M. Gitonga (Nairobi, Kenya) described experiments on intercropping tepary beans and pigeon peas with maize, whereas Julian Jaftha (Pretoria, South Africa) described the isolation of a pigmented, methylotrophic bacterial strain from nodules of Lotononis bainesii, thereby extending an earlier report about the isolation of a methylotrophic strain from a nodule of another South African legume (Moulin et al. 2001). Also, in this session, R. Serraj (Andhra Pradesh, India) presented details about a proposal from ICRISAT (the International Crops Research Institute for the Semi-Arid Tropics) to undertake a Challenge Program on Biological Nitrogen Fixation (CPBNF) as part of a new global initiative engaged in by CGIAR (Consultative Group on International Agriculture Research). The goal of this particular program is to promote BNF technologies in developing countries, particularly in South Asia and Subsaharan Africa, to reduce soil fertility loss, food insecurity, poverty, and malnutrition.

\section{Closing Comments}

The overall conclusion regarding this four-day meeting was that there has been significant progress in BNF research, not only at the molecular and genetics level, but also from the holistic standpoint. Frequently, such disparate viewpoints (reductionist vs. organismic) stand in direct opposition to one another. BNF is a field of study, however, where yin and yang are necessary, and the opposites must work together to develop strategies to deal with a world in which more than 800 million people go to bed hungry. As Ray Dixon (Norwich, U.K.), one of the organizers, said in his final remarks, "The community must support each other." The basic research on genomes, biochemistry, development, and microbiology is critical, but it exists in a vacuum without the incentive of BNF for crop production and soil health. However, funding for research in BNF is at an all-time low in spite of the demands for greater worldwide food security. Frans de Bruijn (Toulouse, France), the final speaker of the conference, noted that, in Europe, legumes are grown on only $5 \%$ of the agricultural land, whereas 20 to $30 \%$ of the land sustains legume crops in the Americas and in Australia. In spite of these numbers, funding for BNF has dropped precipitously in both the U.S.A. and Australia, and a similar trend is taking place in Europe. Scientists who have made significant discoveries in the basic biology of nodulation and nitrogen fixation now face funding uncertainties.

Yet, those of us in the developed world are living at a time when genomes are being sequenced daily and when tremendous information is being generated from microarrays, proteomics, and metabolomics, mostly for biomedical science. In a sense, the emphasis on biomedical research is a "luxury" that 
rests on the fact that few in the developed world are hungry or malnourished; most of us worry about succumbing to cancer or heart disease. However, food security in our countries relies on the production of inexpensive fertilizers, which require cheap oil. Moreover, food now is produced on farms that must be efficiently managed and, as a consequence, are usually very large. Accordingly, the days of the small family farm are numbered, and more and more agriculture in the developed world is becoming industrialized. In his introductory talk, Jules Pretty noted that 219 farms per day are lost annually in the U.S.A., whereas so far, only 11 farms per day are lost in the U.K. He predicted that this latter figure would soon increase. As food production leaves the hands of the small farmer and emanates from agricultural factories, we who have the money gain cheaper and more readily available food, but there are costly side effects, namely, pollution, leaching of nutrients, particularly $\mathrm{N}$ and $\mathrm{P}$, lack of biodiversity, and accumulation of greenhouse gases. It is well known that BNF helps reverse these negative effects. Still, there are other side effects besides those that distress the environment. These affect people and their ability either to grow food or to have enough wealth to buy food from producers. Hunger and food insecurity trap families into poverty, poor health, and ignorance, all of which can persist for generations. Such conditions can create social unrest and political instability. In these days when social and political instability are headline news, governments that neglect the funding of basic and applied agricultural research, such as BNF research, to improve land sustainability and concomitantly food security put their futures at risk.

\section{ACKNOWLEDGMENTS}

We are grateful to the organizers, Ray Dixon, Andy Johnston, Nick Brewin, and Barry Smith for inviting us to write this meeting report. The opinions expressed in it, however, are our own. Our gratitude is also extended to Ray Dixon and to our lab mate Nancy A. Fujishige for valuable comments on the manuscript. We also thank the anonymous reviewers for their helpful comments. We apologize to all those participants whose talks or posters we were unable to reference because of page constraints. Peter De Hoff was supported by an NIH Predoctoral Training Program in Genetic Mechanisms at UCLA (T32-GM07104).

\section{LITERATURE CITED}

Bauer, P., Ratet, P., Crespi, M. D., Schultze, M., and Kondorosi, A. 1996. Nod factors and cytokinins induce similar cortical cell division, amyloplast deposition and Msenod12A expression in alfalfa roots. Plant $\mathrm{J}$. 10:91-105.

Buée, M., Rossignol, M., Jauneau, A., Ranjeva, R., and Bécard, G. 2000. The pre-symbiotic growth of arbuscular mycorrhizal fungi is induced by a branching factor partially purified from plant root exudates. Mol. Plant-Microbe Interact. 13:693-698.

Carroll, B. J., McNeil, D. L., and Gresshoff, P. M. 1985. A supernodulation and nitrate-tolerant symbiotic (nts) soybean mutant. Plant Physiol. 78:34-40.

Christiansen, J., Cash, V. L., Seefeldt, L. C., and Dean, D. R. 2000. Isolation and characterization of an acetylene-resistant nitrogenase. J. Biol. Chem. 275:11459-11464.

Endre, G., Kereszt, A., Kevei, Z., Mihacea, S., Kaló, P., and Kiss, G. B. 2002. A receptor kinase gene regulating symbiotic nodule development. Nature 417:962-966.

Fang, Y., and Hirsch, A. M. 1998. Studying early nodulin gene ENOD40 expression and induction by Nod factor and cytokinin in transgenic alfalfa. Plant Physiol. 116:53-68.

Krusell, L., Madsen, L. H., Sato, S., Aubert, G., Genua, A., Szczyglowski, K., Duc, G., Kaneko, T., Tabata, S., de Bruijn, F., Pajuelo, E., Sandal, N., and Stougaard, J. 2002. Shoot control of root development and nodulation is mediated by a receptor-like kinase. Nature 420:422-426.

Moulin, L., Munive, A., Dreyfus, B., and Boivin-Masson, C. 2001. Nodulation of legumes by members of the beta-subclass of Proteobacteria. Nature 411:948-950.

Nishimura, R., Hayashi, M., Wu, G. J., Kouchi, H., Imaizumi-Anraku, H., Murakami, Y., Kawasaki, S., Akao, S., Ohmori, M., Nagasawa, M. Harada, K., and Kawaguchi, M. 2002. HAR1 mediates systemic regulation of symbiotic organ development. Nature 420:426-429.

Searle, I. R., Men, A. E., Laniya, T. S., Buzas, D. M., Iturbe-Ormaetxe I., Carroll, B. J., and Gresshoff, P. M. 2002. Long-distance signaling in nodulation directed by a CLAVATA1-like receptor kinase. Science. Published online October 31; 10.1126/science.1077937.

Stracke, S., Kistner, C., Yoshida, S., Mulder, L., Sato, S., Kaneko, T., Tabata, S., Sandal, N., Stougaard, J., Szczglowski. K., and Parniske, M. 2002. A plant receptor-like kinase required for both bacterial and fungal symbioses. Nature 417: 959-962.

van Rhijn, P., Fang, Y., Galili, S., Shaul, O., Atzmon, N., Wininger, S., Eshed, Y., Lum, M., Li, Y., To, V., Fujishige, N., Kapulnik, Y., and Hirsch, A. M. 1997. Expression of early nodulin genes in alfalfa mycorrhizae indicates that signal transduction pathways used in forming arbuscular mycorrhizae and Rhizobium-induced nodules may be conserved. Proc. Natl. Acad. Sci. U.S.A. 94:5467-5472. 